\title{
REDUÇÃO DA UMIDADE NO PELLET FEED DA USINA CONCEIÇÃO I*
}

\author{
Paulo Henrique Vieira Soares ${ }^{1}$ \\ Wanderson Jesus ${ }^{2}$ \\ Rogério Francisco de São José3 \\ Lucas Gomes ${ }^{4}$ \\ André Bolinelli Aguiar ${ }^{5}$ \\ Vicentino José Pinheiro Rodrigues ${ }^{6}$ \\ José Cláudio dos Santos Satyro ${ }^{7}$
}

\section{Resumo}

A filtragem vertical no processo de mineração representa a etapa final de beneficiamento do minério de ferro, pois o material proveniente das etapas anteriores chega em forma de polpa até os filtros verticais a vácuo que por sua vez tem a função de retirar a umidade do material, reduzindo a níveis aceitáveis de forma a propiciar a estocagem do produto no pátio de armazenamento. Este trabalho aborda o uso de análise estatística empregado no processo de filtragem da usina de Conceição I para redução da umidade no pellet feed.

Palavras-chave: Filtragem vertical, minério de ferro, produtividade, umidade.

\section{REDUCTION OF MOISTURE IN THE PELLET FEED OF THE USINA CONCEIÇÃO I}

\section{Abstract}

The vertical filtration in the mining process represents the final step of iron ore beneficiation since the material from the previous steps arrives in the form of pulp up to the vertical vacuum filters which in turn has the function of removing the moisture from the material reducing To acceptable levels in order to provide product storage in the storage yard. This work addresses the use of statistical analysis used in the filtration process of the Conceição I plant to reduce moisture in the pellet feed.

Keywords: Vertical filtration, iron ore, productivity, moisture.

1 Engenheiro eletricista formado pelo Centro Universitário do Leste de Minas Gerais, engenheiro de automação na gerência de automação, energia, telecomunicações e combustíveis, VALE S/A, Itabira, Minas Gerais, Brasil.

2 Engenheiro metalúrgico formado pelo Universidade Federal de Ouro Preto, engenheiro de processo na gerência de operação das usinas Conceição I e Conceição II, VALE S/A, Itabira, Minas Gerais, Brasil

3 Administrador de empresas pela Fundação Comunitária de Ensino Superior de Itabira, técnico especializado de operação na gerência de operação das usinas Conceição I e Conceição II, VALE S/A, Itabira, Minas Gerais, Brasil.

4 Engenheiro de minas formado pelo Universidade Federal de Ouro Preto, Gerente de operação das usinas Conceição I e Conceição II, VALE S/A, Itabira, Minas Gerais, Brasil.

5 Ciência da Computação, formado pela Universidade Federal de Minas Gerais, Analista operacional especialista na gerência de melhorias operacionais, VALE S/A, Belo Horizonte, Minas Gerais, Brasil.

6 Engenheiro eletricista formado pelo Universidade Federal de Minas Gerais, Gerente de automação, energia, telecomunicações e combustíveis, VALE S/A, Itabira, Minas Gerais, Brasil.

7 Engenheiro de produção pela Fundação Comunitária de Ensino Superior de Itabira, Analista de automação na gerência de automação, energia, telecomunicações e combustíveis, VALE S/A, Itabira, Minas Gerais, Brasil. 


\section{INTRODUÇÃO}

O filtro a vácuo de discos tem a função de separar o líquido (água) e as partículas sólidas da polpa de concentrado por meio de pressão de sucção negativa (vácuo), a água passa pelo tecido (elemento filtrante), enquanto a parte sólida se aloja nos discos em movimento antes do ciclo secante, formando peças sólidas (torta final). $\mathrm{O}$ equipamento é composto de vários discos, cada um formado por setores interdependentes conforme Figura 1.

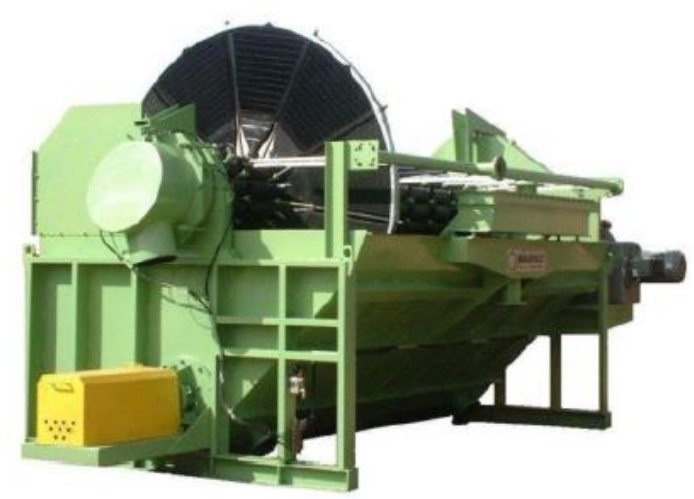

Figura 1. Filtros a vácuo de discos.

O circuito da filtragem é composto basicamente pelos filtros verticais, tanque separador de filtrado, pernas barométricas e bombas de vácuo. A polpa de minério de ferro que chaga do processo anterior é depositada na bacia do filtro, nesse momento ocorre três etapas sendo: Formação; Secagem e Desprendimento.

$\mathrm{Na}$ formação, mediante uma bomba de vácuo, cria-se uma sucção que força o líquido filtrado a atravessar a tela filtrante. Este líquido ingressa no setor e em seguida percorre os dutos, passando pelo tubo longitudinal até chegar a um tanque separador de filtrado. O separador tem uma saída para a bomba de vácuo e outra para a perna barométrica, que leva o filtrado para um tanque externo. Na sequência a sucção ainda se mantém quando os setores abandonam a polpa. Nesta etapa, não ocorre mais a acumulação de partículas sólidas na superfície da tela filtrante, porém, a solução filtrada continua sendo extraída da mesma forma que na etapa anterior. Assim, o concentrado vai diminuindo sua umidade à medida que o disco gira. Por fim, quando os setores passam entre os chutes de descarga do filtro, a pressão positiva, aplicada mediante um compressor externo, atinge a zona de sopro, desse modo, ao inflarem-se as telas filtrantes por efeito da pressão, o concentrado aderido desprende-se [1]. A Figura 2 ilustra o circuito da filtragem e as etapas descritas anteriormente.

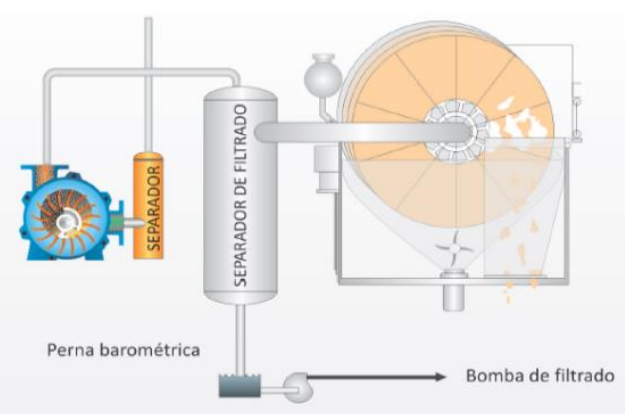

Figura 2. Funcionamento do filtro a vácuo de discos. 


\section{MATERIAIS E MÉTODOS}

Este trabalho é caracterizado como uma pesquisa descritiva, baseada em observações e análise dos problemas durante a realização e aplicação do trabalho de Seis Sigma no processo de filtragem vertical. Essa é uma metodologia de melhoria e otimização de processos, que requere dados e análises estatísticas como forma de medição e melhoramento do desempenho operacional das organizações [2].

A filtragem é o último processo do beneficiamento do minério de ferro e tem como principal objetivo a retirada da umidade da polpa. A indisponibilidade da filtragem impacta diretamente na produção final da planta. Com o início da operação do projeto de adequação da Usina de Conceição I (CE I) no final de 2014, a produção de Pellet Feed (PF) aumentou, fazendo-se necessária uma maior disponibilidade física (DF) do processo de filtragem vertical. Existia na usina de Conceição I um déficit na disponibilidade dos filtros e demais integrantes do processo de filtragem. $O$ circuito existente era composto por doze filtros de $80 \mathrm{~m}^{3}$ e doze bombas de vácuo, para atender a nova demanda foram instalados mais seis filtros de $120 \mathrm{~m}^{2}$ e seis bombas de vácuo. Após a interligação da usina nova com a usina existente o circuito de filtragem passou a trabalhar "sobrecarregado", mesmo na fase de ramp-up a filtragem já chamava a atenção pelos seus indicadores aquém do projetado. Nessa etapa foi decidido, pela área gerencial da empresa, que era necessário criar uma equipe multidisciplinar para focar na análise e intervenção, garantindo de forma sustentável os resultados e a condição de operação com taxa nominal.

\section{RESULTADOS E DISCUSSÃO}

A origem da água livre no minério está relacionada com a sua característica física, mas o beneficiamento realizado a úmido aumenta a umidade. Processos como a flotação, usada para aumentar o teor de ferro do minério, usam água. A água representa um dispêndio maior no seguro da carga transportada no navio, e, em alguns casos, pode provocar a interrupção de um carregamento no porto. A legislação internacional, Transportable Moisture Limit (TML), regulamenta que 0 limite máximo da umidade é de $10,45 \%$, por exemplo, para certa região de embarque do minério de ferro. Quando o percentual de umidade ultrapassa o limite de TML no carregamento, o comandante do navio pode suspender a operação. E aí é preciso correr contra o tempo para fazer a blendagem (mistura) de minério no pátio e, assim, reduzir a umidade e reiniciar o carregamento. Isso tudo representa perda por lucro cessante [3]. É possível perceber na Figura 3 um aumento significativo no valor da umidade, que passou de aproximadamente 9\% em junho de 2014 para cerca de 10,5\% em junho de 2015. 


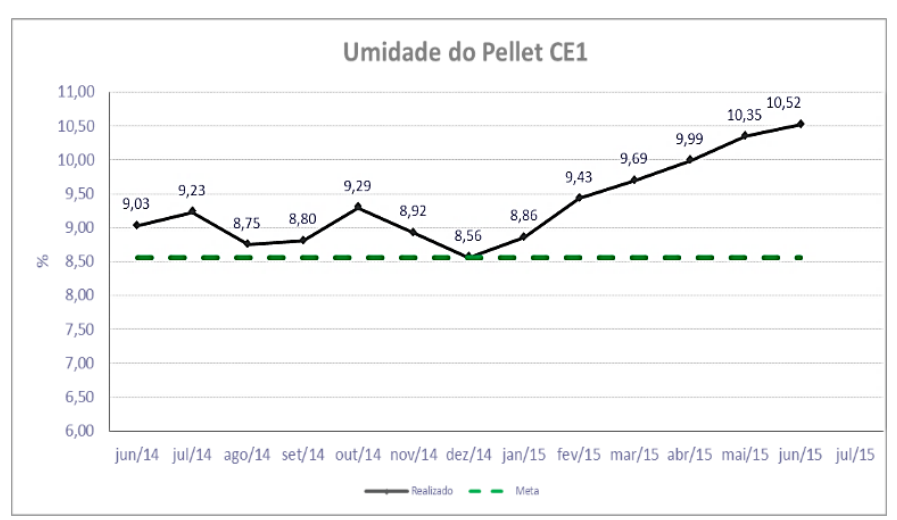

Figura 3. Umidade do Pellet Conceição I.

No mesmo período a taxa unitária da filtragem (TUF), definida e calculada internamente pela equação 1, teve máximo de 2,54 e mínimo de 1,92.

$$
T U F=\frac{\text { Tonelada } / \text { hora }}{n^{\text {o }} \text { de filtros funcionando }}
$$

Devido à área dos filtros novos ser maior que a área dos filtros existentes, foi inserida a ponderação no denominador para cálculo da TUF.

Conhecendo-se o histórico da umidade e os impactos do valor elevado deste indicador, foi definido como desafio deslocar a média para o valor de 8,56\%, que representa o benchmark do período analisado. Analisando-se as 5 equipes que trabalham de turno, sendo estas denominadas: Letra $A$; $B$; $C$; D e $E$, pode-se observar na Tabela 1 que a média possui aproximadamente o mesmo valor, isso indica que tem-se um padrão de operação (que sempre pode ser melhorado) e que os problemas primários encontram-se no processo.

Tabela 1. Análise do fenômeno

\begin{tabular}{lccccccc}
\hline Turma & № & Mínimo & $\begin{array}{c}\mathbf{1 0}^{\mathbf{0}} \\
\text { Quartil }\end{array}$ & Mediana & $\begin{array}{c}\mathbf{3}^{\circ} \\
\text { Quartil }\end{array}$ & Máximo & Média \\
\hline Equipe A & 15 & 8,36 & 8,71 & 9,11 & 9,73 & 10,81 & 9,31 \\
\hline Equipe B & 15 & 8,49 & 8,78 & 9,12 & 9,87 & 10,47 & 9,36 \\
\hline Equipe C & 15 & 8,61 & 9,03 & 9,11 & 9,98 & 10,69 & 9,45 \\
\hline Equipe D & 15 & 8,23 & 8,86 & 9,31 & 10,02 & 10,44 & 9,40 \\
\hline Equipe E & 15 & 8,21 & 8,87 & 9,18 & 9,65 & 10.49 & 9,28 \\
\hline
\end{tabular}

Realizando-se o teste de normalidade, mostrado na Figura 4(a), tem-se que os dados não seguem uma distribuição normal (Pvalor $<0,05$ ), com isso a carta de controle não é a ferramenta indicada para análise do fenômeno. Porém a Figura 4(b) ilustra como o processo se mostrou instável com presença de vários pontos de causas especiais provavelmente originados por mudança de cenário, sendo as causas especiais superiores provenientes da instabilidade do sistema de geração de vácuo dos filtros de $40 \mathrm{~m}^{2}$, que provocou o aumento expressivo da umidade, já as causas especiais inferiores se devem ao aumento da utilização dos novos filtros de $120 \mathrm{~m}^{2}$. 


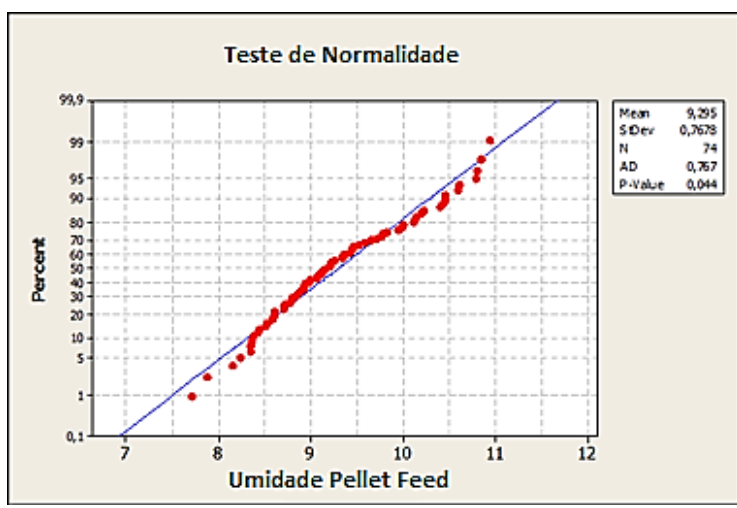

Figura 4(a). Teste de normalidade

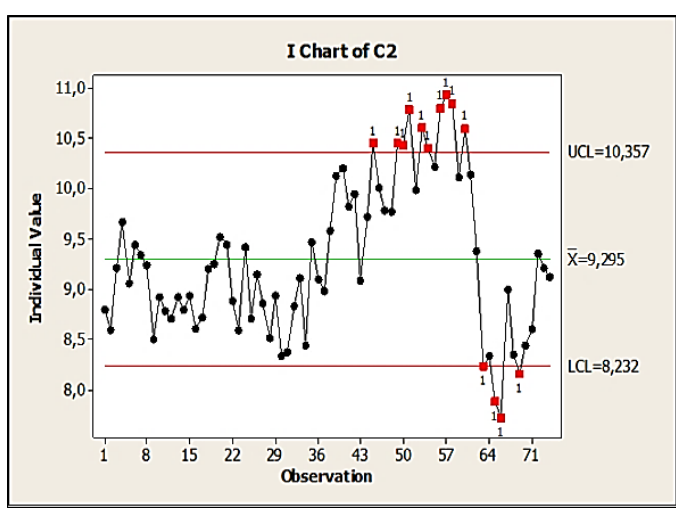

Figura 4(b). Análise da variação

Analisando-se os dados no histograma da Figura 5(a), o percentual esperado fora da faixa de especificação é de $82,99 \%$ considerando-se a variabilidade natural, e 98,02\% considerando-se a variabilidade total Eliminou-se então (para análise) as causas especiais e fez-se um novo histograma e teste normal. O Pvalor ficou acima de 0,10 , o que comprova que a umidade segue a distribuição normal.

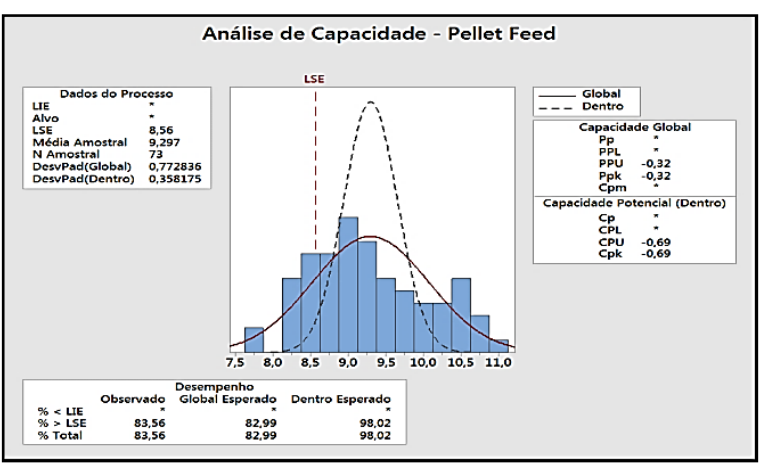

Figura 5(a). Teste de capacidade

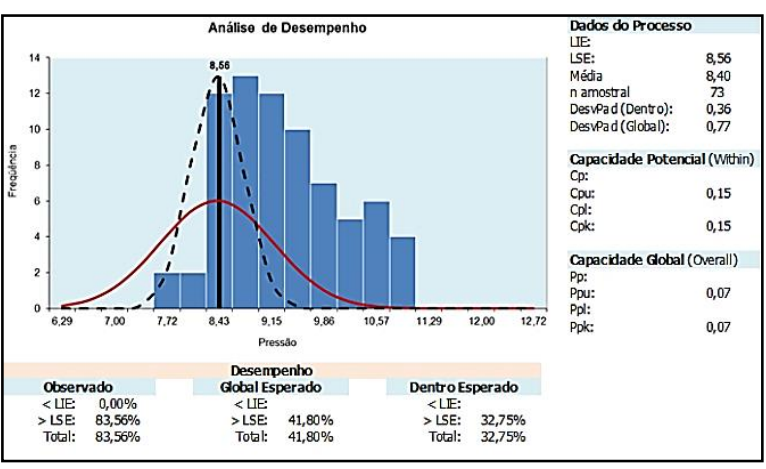

Figura 5(b). Análise de desempenho

Assim adotou-se, com relação ao Pellet Feed, a estratégia de deslocamento de média e redução do número de causas especiais. Realizou-se a análise de desempenho deslocando-se a média de 9,27 para 8,4 (para a meta de LSE $=8,56$ ). Ao utilizar essa nova média, pode-se verificar na Figura 5(b) que o percentual total esperado fora da faixa de especificação, considerando-se a variabilidade natural, encontra-se em $32,75 \%$, e, considerando-se a variabilidade total, $41,8 \%$.

\subsection{Análise do processo}

No circuito de saída da usina de beneficiamento tem-se o espessador de concentrado que recebe a polpa de PF. Na parte superior deste, ocorre a recuperação de água, e na parte inferior tem-se a saída do minério de ferro que possui densidade superior à da agua e é adensado até o fundo do equipamento, de onde o mesmo é bombeado até o agitador. O agitador é peça importante e tem a função de homogeneizar a polpa que será bombeada até o distribuidor/filtro verticais. A bomba de vácuo junto com o filtro realiza o processo de secagem e por fim as correias transportam o minério de ferro, já seco, até o pátio de estocagem. 


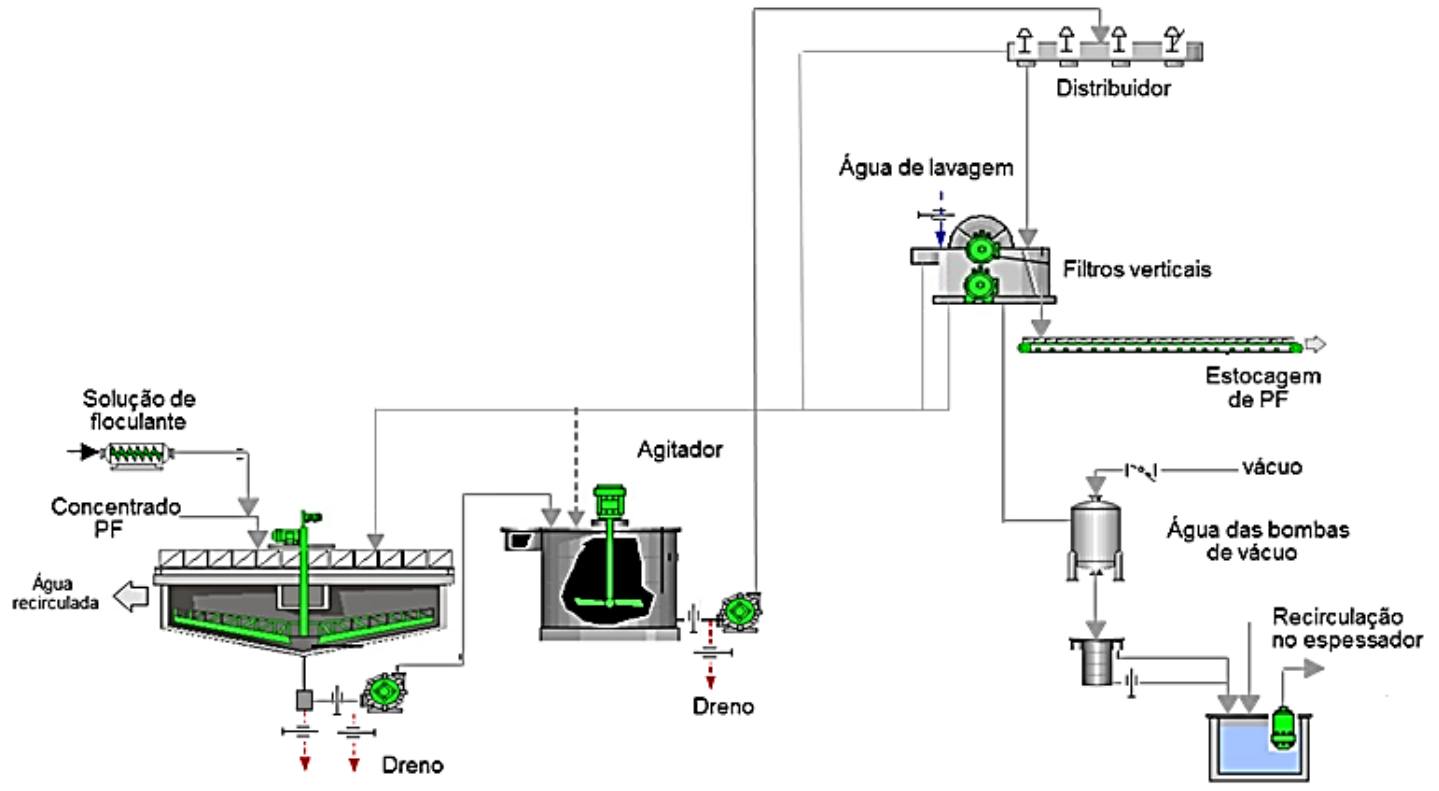

Figura 6. Circuito da filtragem

Conhecendo o processo, realizou-se o mapeamento dos parâmetros do mesmo, os ruídos e os parâmetros do processo crítico. Na composição da árvore de falha ou fault tree analysis (FTA), levantou-se 17 possíveis causas para o problema da umidade elevada. Posteriormente, foi realizada, pela equipe de trabalho, a priorização destas causas, em que foram definidos pesos para: Contribuição para ocorrência do problema; Segurança; Urgência; e Autonomia. Após atribuir as notas a priorização foi realizada de forma a atender os itens que apresentaram o maior valor no somatório final.

\subsection{Comprovação das causas}

O primeiro item observado diz respeito à queda de água ou matéria sobre a correria de saída da filtragem, encontrou-se vários pontos de vazamento após a filtragem e antes do ponto de coleta para amostra. A Tabela 2 apresenta os valores para as duas condições.

Tabela 2. Umidade versus vazamento

\begin{tabular}{lcc}
\hline & Sem vazamento & Com vazamento \\
\hline Código da amostra & $01: 06$ & $01: 03$ \\
\hline Hora & $09: 42$ & $09: 50$ \\
\hline Umidade & $6,56 \%$ & $9,27 \%$ \\
\hline \multicolumn{3}{c}{ Amostra de 02/02/2017 - TC6775 } \\
\hline
\end{tabular}

$\mathrm{Na}$ sequência analisou-se os filtros $1410 \mathrm{CC} 19$ e 20 operando com tecido filtrante danificado. Conforme Tabela 3 percebe-se que a tela rasgada não apresentou impacto sobre a umidade, porém essa condição fragiliza e influencia na disponibilidade do equipamento necessitando ser tratada.

Tabela 3. Umidade versus telas rasgadas

\begin{tabular}{lcc}
\hline & Fl1410CC19 & Fl1410CC20 \\
\hline Código da amostra & $14: 06$ & $14: 03$ \\
\hline Hora & $14: 00$ & $13: 55$ \\
\hline Pressão de vácuo & $15,5 \mathrm{polHg}$ & $15,8 \mathrm{polHg}$ \\
\hline
\end{tabular}




\begin{tabular}{lcc}
\hline Densidade & 1,99 & 1,95 \\
\hline $\mathrm{pH}$ & 7,83 & 7,97 \\
\hline Velocidade dos filtros & $1,5 \mathrm{rpm}$ & $1,68 \mathrm{rpm}$ \\
\hline $\begin{array}{l}\text { Presença de espuma } \\
\text { na bacia do filtro }\end{array}$ & $\mathrm{Sim}$ & $\mathrm{Sim}$ \\
\hline Umidade & $7,78 \%$ & $7,38 \%$ \\
\hline
\end{tabular}

Amostra de 02/02/2017

Posteriormente, realizou-se um experimento de 2 fatores sem réplica para avaliar se o nível da bacia e a velocidade do disco impactam significativamente na umidade. $\mathrm{Na}$ Figura 7, para que um fator seja significativo é necessário que ele cruze a linha de Lenth. Por regra geral, nenhum dos dois fatores são significativos. Porém pela exceção da regra, ao utilizar dois fatores, considera-se significativo o que mais se aproximou da linha de Lenth, neste caso o nível da bacia (fator B).

Tabela 4. Umidade versus velocidade

\begin{tabular}{lcc}
\hline Fatores & Níveis & Níveis \\
\hline Velocidade do disco $(\mathrm{A})$ & $1 \mathrm{rpm}(-1)$ & $1,5 \mathrm{rpm}(+1)$ \\
\hline Bacia $(\mathrm{B})$ & Vazia $(-1)$ & Cheia $(+1)$ \\
\hline
\end{tabular}

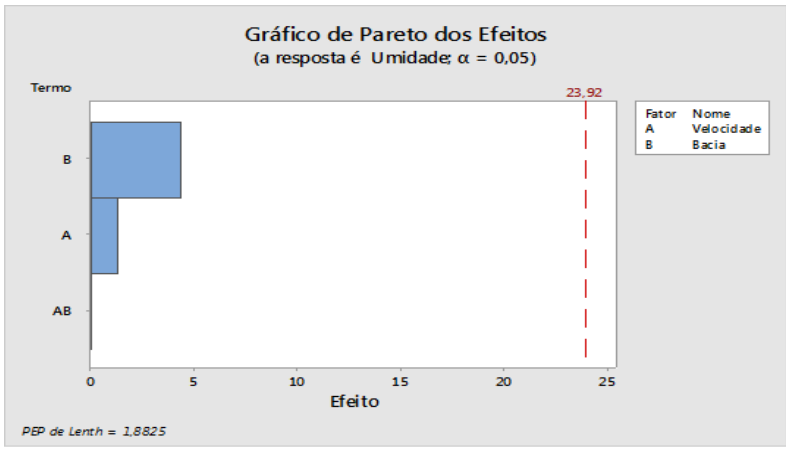

Figura 7(a). Teste de capacidade

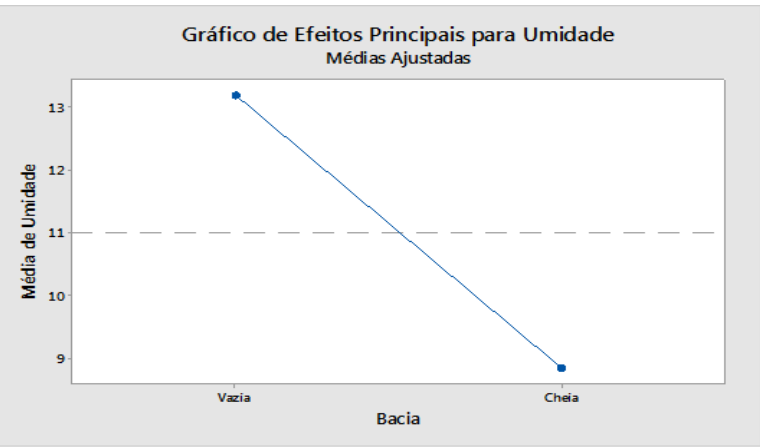

Figura 7(b). Análise de desempenho

Ao fazer o gráfico de efeitos principais que afetam a umidade, verificou-se que quando a bacia se encontra cheia, obtém-se os melhores resultados de umidade. Outro ponto importante visto na análise de regressão foi a presença de relação entre número de filtros funcionamento e a TUF apenas quando a bacia estava cheia.

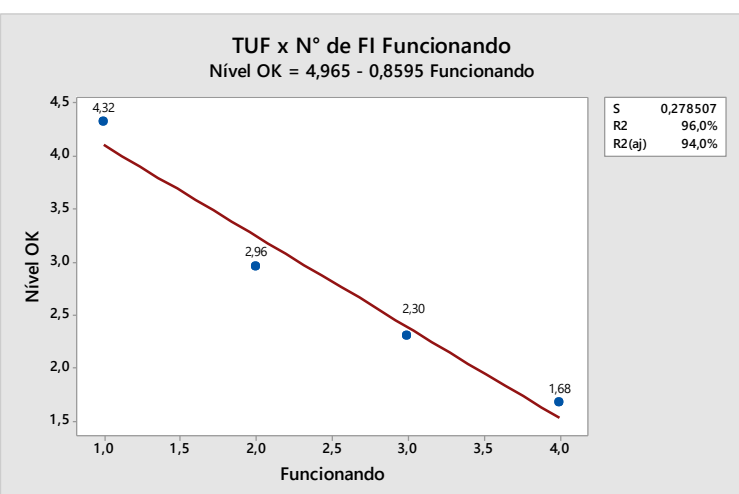

Figura 8(a). Bacia cheia

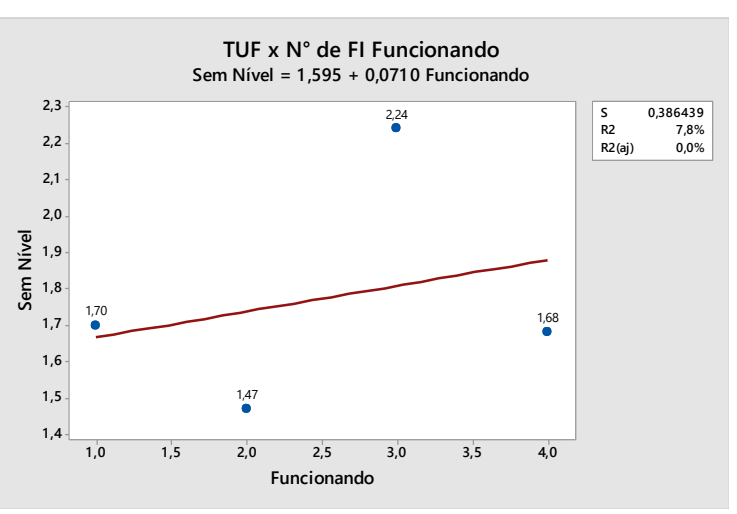

Figura 8(b). Bacia vazia

Por fim, verificou-se a umidade por família de filtros, coletado amostradas dos filtros de $40 \mathrm{~m}^{2}$ e $120 \mathrm{~m}^{2}$. A tabela 5 mostra o teste de Levene, como o P-valor $>0,05$, não existe diferença significativa entre as variabilidades dos processos. 
Tabela 5. Teste de Levene

\begin{tabular}{rr}
\hline Tipo & $p$-va/or \\
\hline Média & 0,239 \\
Mediana & 0,370 \\
Média & 0,239 \\
s/Extremos & \\
\hline
\end{tabular}

Pela Análise de variâncias ANOVA, pode-se observar que as médias são diferentes, uma vez que P-value na Tabela 6 é menor que 0,05.

Tabela 6. Análise de variância

\begin{tabular}{|c|c|c|c|c|c|c|}
\hline Fonte de Variação & SS & $d f$ & MS & F & $P$-value & F Cri \\
\hline Entre Grupos & 14,72 & 1 & 14,72 & 33,13 & 0,0003 & 0,00 \\
\hline Dentro Grupos & 4,00 & 9 & 0,44 & & & \\
\hline Total & 18,71 & 10 & & & & \\
\hline
\end{tabular}

Na Figura 9 é possível visualizar a diferença da umidade média entre os filtros de $40 \mathrm{~m}^{2}$ e $120 \mathrm{~m}^{2}$.

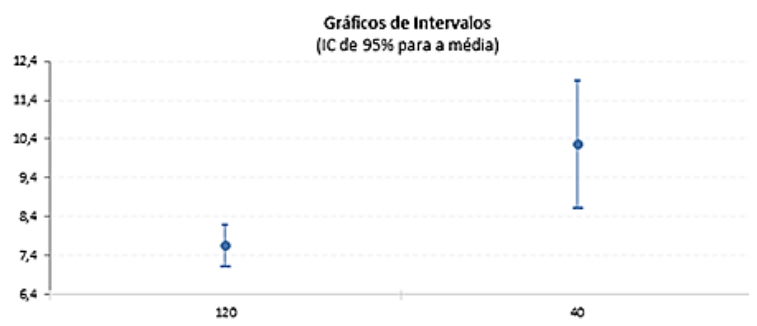

Figura 9. Gráfico de intervalos

\subsection{Atuação nas causas}

Devido a tendência observada na Figura 10, de aumento da utilização dos filtros de $120 \mathrm{~m}^{2}$, somado aos constantes furos nas bacias dos filtros de $40 \mathrm{~m}^{2}$, decidiu-se que os esforços seriam aplicados na filtragem nova e os trabalhos desprendidos nos filtros de $120 \mathrm{~m}^{2}$.

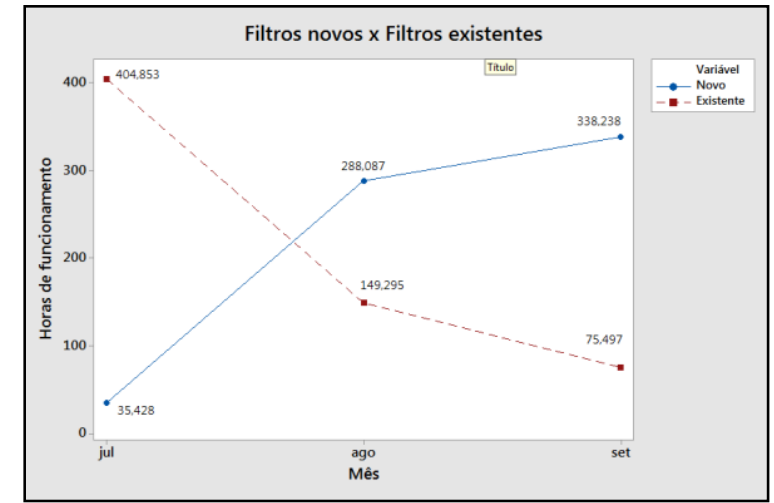

Figura 10. Horas de funcionamento

Definiu-se a velocidade de trabalho do equipamento em 1,5 rpm para a condição operacional. 
Para equalizar a pressão e uniformizar a distribuição da alimentação que chega nos filtros, foi confeccionado pela equipe Vale um distribuidor pressurizado (Figura 11) em substituição ao distribuidor anterior que funciona por gravidade.

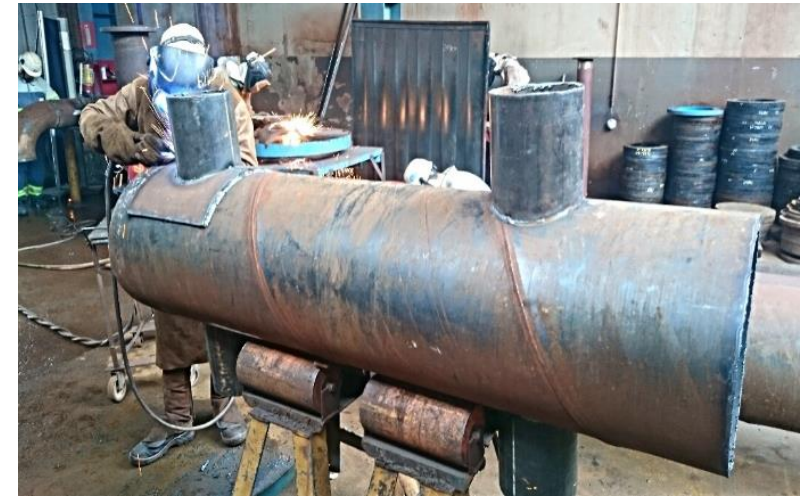

Figura 11(a). Confecção do distribuidor

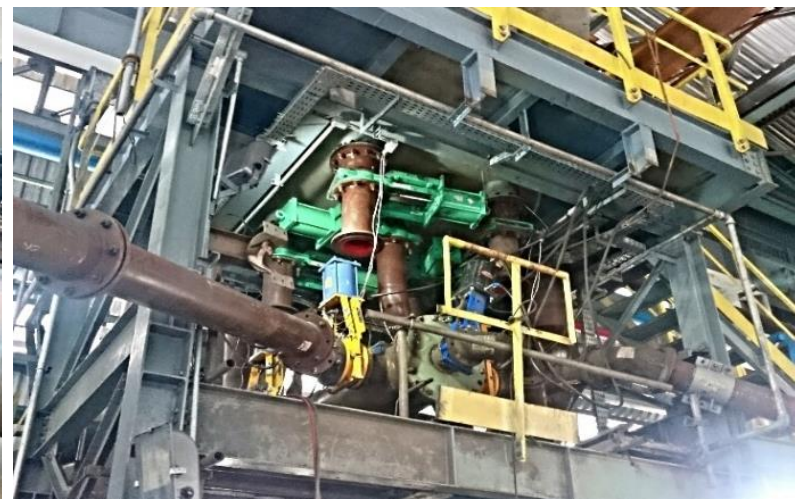

Figura 11(b). Montagem do distribuidor

Junto com a troca da peça, modificou-se a posição das válvulas de alimentação dos filtros que originalmente são montadas na horizontal e por muitas vezes, por questão de alinhamento ou material na sede da lâmina, não possibilitava o ciclo da mesma. A falha no fechamento desta válvula impede a limpeza eficaz do equipamento, que permanece sendo alimentado com polpa de minério durante esse processo.

A bomba de vácuo é responsável por produzir pressão negativa utilizada na secagem da polpa do minério de ferro. Para gerar vácuo deve-se controlar a injeção de água de selagem da bomba. Durante os trabalhos colocou-se válvulas de controle proporcional (Figura 12-b) no circuito de água de selagem, garantindo um ajuste proporcional de forma a controlar a água de selagem para trabalho no "ponto ótimo" do equipamento, pois as válvulas existentes eram do modelo alto-operada (Figura 12-a) que garantem o controle durante condições normais do processo, porém não conseguem responder na ocorrência de distúrbios na pressão da linha.

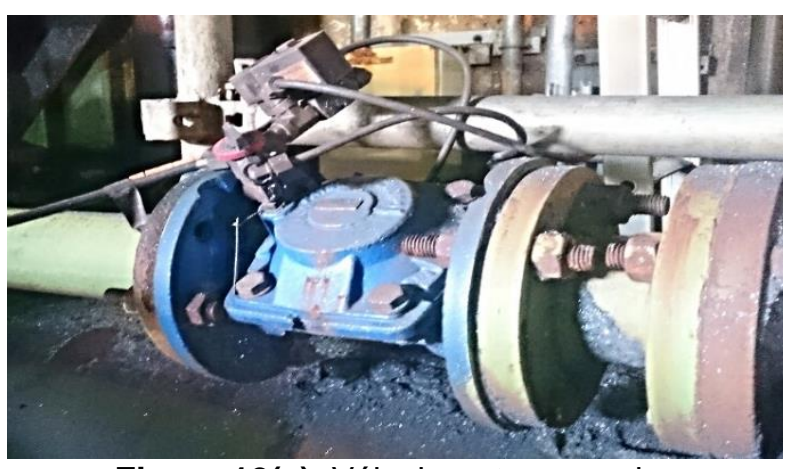

Figura 12(a). Válvula auto-operada

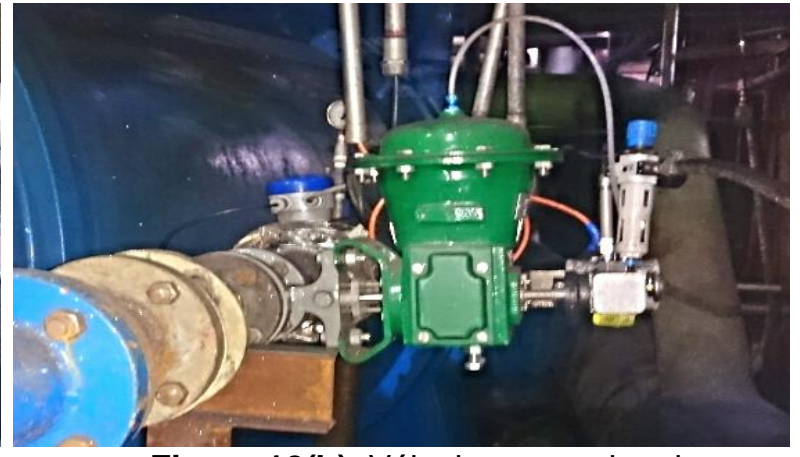

Figura 12(b). Válvula proporcional

Um dos pontos que mais afeta a produtividade dos filtros é quando ocorre a "cegueira" do tecido filtrante, por isso é de grande importância a limpeza periódica dos filtros. Visando melhorar a limpeza do equipamento em automático, foram substituídas as válvulas de dreno da bacia do modelo guilhotina (Figura 13-a) pelo modelo mangote (Figura 13-b). Desta forma evita-se os recorrentes travamentos das válvulas guilhotina devido a presença de material na sede. 


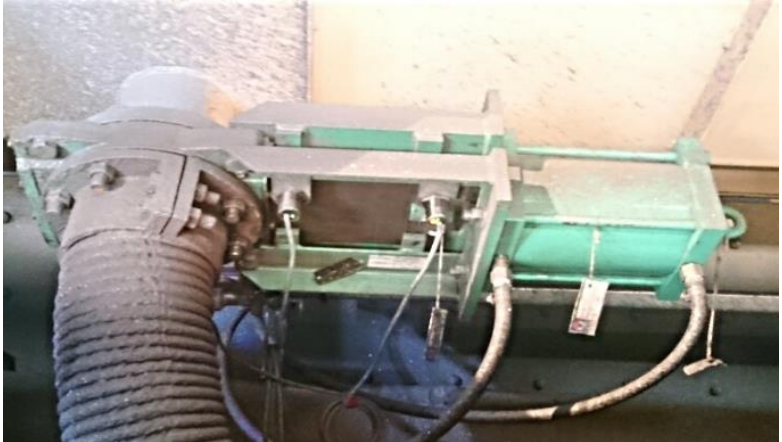

Figura 13(a). Válvula auto-operada

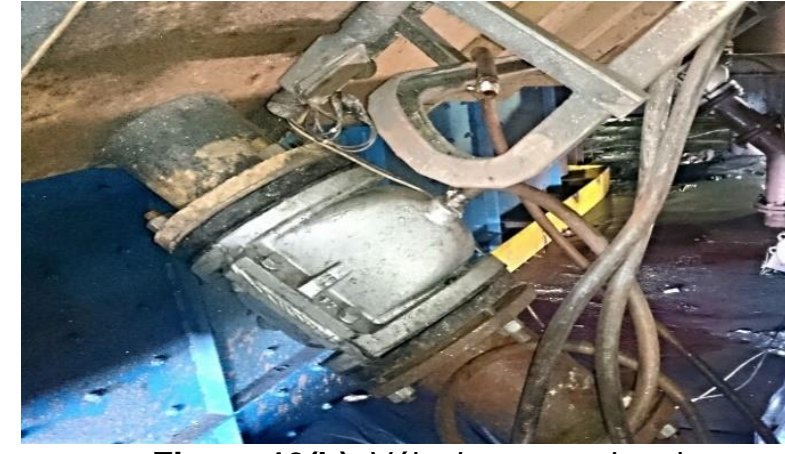

Figura 13(b). Válvula proporcional

Por fim implementou-se rotas operacionais para que o operador verifique todos os parâmetros da área (Figura 14-a), criou-se tela no PIM's com farol de status Normal $x$ Anormal dos principais indicadores da filtragem e desenvolveu-se no PLC a lógica para controle automático da alimentação da filtragem em função do número de filtros em funcionamento.

\begin{tabular}{|c|}
\hline Rota Operacional Filtragem Vertical \\
\hline $\begin{array}{l}\text { - Acessar a filtragem pela escada de acesso } \\
\text { próximo a TC6770; }\end{array}$ \\
\hline $\begin{array}{l}\text { Inspecionar as correias de produto } 6765 \text { e } \\
6775 \text { : umidade, obstruçăo e produtividade; }\end{array}$ \\
\hline $\begin{array}{l}\text { Inspecionar os ciclones de adensamento } \\
6475 \text { e } 1410 \mathrm{CC} 03 \text {, pressäo (ideal de } 1,5 \text { a } 2,5 \\
\mathrm{kgg} f^{\prime} \mathrm{cm}^{2} \text { ) e condiçōes operacionais }\end{array}$ \\
\hline $\begin{array}{l}\text { - Inspecionar o agitador } 6521 \text {, sistema de } \\
\text { lubrificaçäo e fluxos de alimentação: }\end{array}$ \\
\hline $\begin{array}{l}\text { - Inspecionar os potes barométricos quanto a } \\
\text { obstrução, agua e drenos. }\end{array}$ \\
\hline $\begin{array}{l}\text {-Inspecionar as bombas de vácuo, } \\
\text { funcionamento, vazåo de água (mínimo de } \\
60 \mathrm{~m}^{t} / \mathrm{h} \text { ) e pressäo (13polHg) }\end{array}$ \\
\hline $\begin{array}{l}\text {-Inspecionar os filtros que estäo em } \\
\left.\text { operação, pressăo de sopro (1,5 kgf/ } / \mathrm{cm}^{2}\right) \text {, } \\
\text { telas, umidade e produtividade; }\end{array}$ \\
\hline $\begin{array}{l}\text { - Inspecionar as peneiras de alta frequência, } \\
\text { alimentação, obstrução, água de spray. } \\
\text { sobrecarga e vazamentos; }\end{array}$ \\
\hline $\begin{array}{l}\text { - Acessar a cabine e realizar leitura das } \\
\text { variáveis no Pl e intervir de acordo com o } \\
\text { processo. }\end{array}$ \\
\hline
\end{tabular}

Figura 14a). Rota operacional

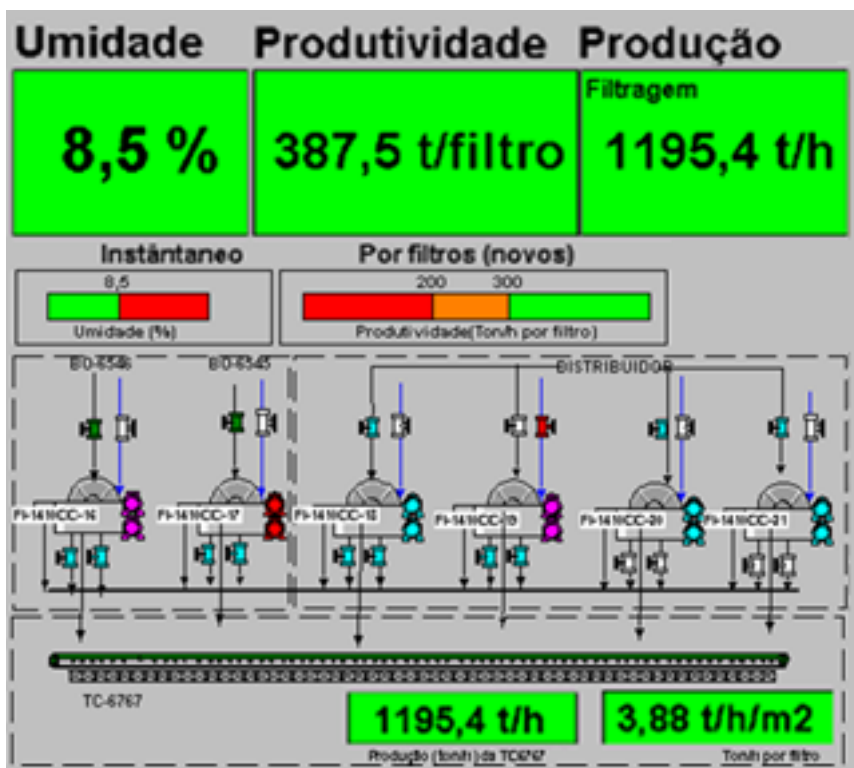

Figura $1 \overline{4(b)}$. Indicadores da filtragem 


\subsection{Resultados}

Após um plano de ação com mais de 25 itens, dos quais 10 foram priorizados e todos executados no período de Dez/16 a Abr/17, obteve-se o resultado apresentado na Figura 15. Observa-se que o resultado é sólido, pois mesmo após o período de verificação, entre Outubro e Dezembro os valores permaneceram abaixo da meta.

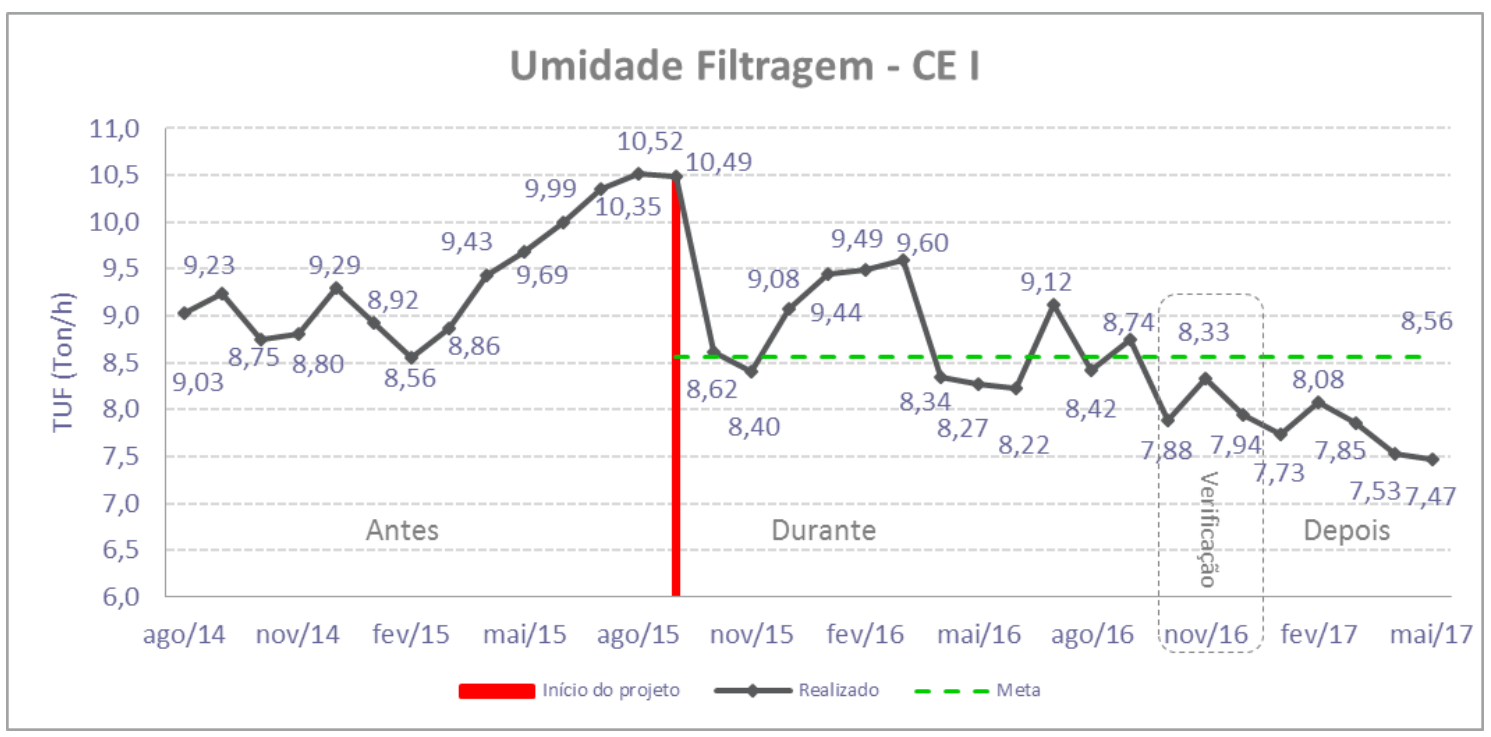

Figura 15. Umidade

O desvio apresentado no mês de Set/16 reflete o entupimento da perna barométrica como consequência de tela rasgada. Essa é uma causa mapeada e que a princípio não apresentou relação com a umidade. Porém quando os filtros operam com tela rasgada por um longo período, o reflexo é sentido pelas pernas barométrica que são obstruídas, prejudicando a performance das bombas de vácuo e consequentemente aumentando a umidade do produto. Como medida de controle foram reciclados todos os operadores e inserido a verificação de tela resgada na rota operacional.

\section{CONCLUSÃo}

Após o término do projeto, a média do indicador de umidade foi deslocada para baixo, passando de $9,34 \%$ para $8,43 \%$, enquanto a TUF foi elevada de $2,2 \mathrm{ton} / \mathrm{h} / \mathrm{m}^{2}$ para $3,4 \mathrm{ton} / \mathrm{h} / \mathrm{m}^{2}$ no terceiro trimestre de 2016. Nota-se que o resultado é consistente uma vez que os valores de umidade praticados nos primeiros meses de 2017 são inferiores a meta definida inicialmente. Com isso foi estimado uma economia anual de aproximadamente US\$1.5MM, isso se deve ao fato que perdíamos com transporte, manuseio e armazenamento de "água" que ocupa espaço nessas etapas e não é um produto que o cliente compra. Além da redução nos riscos de emborcamento de navios e redução nos entupimentos e atrasos no carregamento.

Os ganhos apresentados pelo projeto são potenciais, porque, apesar de ter sido submetido ao período de verificação e superado a sua meta, variáveis geradas pelo projeto de Adequação Conceição I podem alterar tanto a produção anual quanto a umidade do produto. 
A água presente no minério (umidade) é descontada do preço final do produto (não existe perda de receita), entretanto a redução significativa deste "contaminante" traz ganhos expressivos para toda a cadeia do minério de ferro, com redução de custos no manuseio do subproduto nos pátios de estocagem, ferrovias, navios, centros de distribuição e no cliente.

\section{REFERÊNCIAS}

1 AUTOMATION, A; TECNOLOGIA, T, P. Manual de operações - Cauê. Área 1410EE Usina de Concentração/Filtragem.1ํㅡ. Ed. Itabira. 2014, 6 p.

2 Lameira R. A Metodologia. [acesso em 08 jun. 2017]; Disponível em: http://sixsigmabrasil.com.br/pag_metodologia.html.

3 Vale@informar - http://www.vale.com/brasil/PT/aboutvale/news/Paginas/itv-de-ouropreto-testa-equipamento-que-reduz-umidade-do-minerio-de-ferro.aspx 